\title{
MELHORES CONDIÇões de TRABALHO COMO PREMISSA PARA A PROFISSIONALIZAÇÃO DOCENTE
}

\section{BETTER WORKING CONDITIONS AS PREMISES FOR TEACHING PROFESSIONALISM}

\author{
SILVA, Amanda Moreira da ${ }^{1}$
}

\begin{abstract}
RESUMO
No presente artigo buscamos contextualizar os princípios de valorização do profissional do magistério público, inscritos na Resolução no 2/2015, que define as Diretrizes Curriculares Nacionais para a formação inicial em nível superior e para a formação continuada. O objetivo foi analisar a valorização do magistério conforme esta Resolução, reconhecendo a materialidade das políticas em curso, que vem gerando uma metamorfose no mundo do trabalho docente nas redes municipais e estaduais de ensino. Nossa análise teve como pano de fundo a atual conjuntura de privatização e mercantilização da educação pública, via terceirização e flexibilização do trabalho docente, mediante o recorte teóricometodológico do materialismo histórico-dialético operado por Antonio Gramsci. Nesse sentido, confrontamos os princípios postos na Resolução no 2/2015, com a atual conjuntura de precarização do trabalho docente que indicam um novo formato de "regime de colaboração com o empresariado", cujo objetivo é imprimir nas instituições de ensino públicas o ethos empresarial e o trabalho flexível.
\end{abstract}

PALAVRAS-CHAVE: Trabalho docente; Precarização; Privatização.

\begin{abstract}
In this article we seek to contextualize the principles of professional valorization in public teaching, as it is set in Resolution CNE/CP $\mathrm{n} / 2 / 2015$, which defines the Curriculum Guidelines for initial and continued qualification in higher education. The objective was to analyze the valorization of the teaching profession according to this Resolution recognizing the materiality of the policies underway that has been generating a metamorphosis in the world of teaching work in the municipal and state teaching networks. Our analysis had as background the current conjuncture of privatization and mercantilization of public education, through outsourcing and flexibilization of the teaching work, and this is done through the theoretical and methodological framework of historical materialism operated by Antonio Gramsci. In this sense, we confront the principles set forth in Resolution N02/2015, with the current situation of precariousness of the teaching work that indicates a new approach to "regimens of collaboration with the business community", with the objective to imprint in public education the business ethos and the flexible work.
\end{abstract}

KEYWORDS: Teacher Labor; Deterioration; Privatization.

\footnotetext{
${ }^{1}$ Professora Assistente de Educação Física do Instituto de Aplicação da Universidade do Estado do Rio de Janeiro / CAp-UERJ
} 


\section{INTRODUÇÃO}

O presente artigo analisa o contexto de regulamentação das 'Diretrizes Curriculares Nacionais para a Formação Inicial e Continuada dos Profissionais do Magistério da Educação Básica ${ }^{2 \prime}$ mediante um recorte teórico e metodológico da Resolução no 2/2015, no que diz respeito às possíveis contradições nas estratégias de implementação dos princípios desta política de valorização dos profissionais do magistério público. Os objetivos da resolução são confrontados com a atual política privatista e mercantilista para educação pública, cujo foco é incidir na "(con) formação" dos profissionais do magistério e na flexibilização das suas condições de trabalho. Um processo que está integrado em um crescente "movimento orgânico" das superestruturas complexas do desenvolvimento e expansão do capital na educação pública, onde o empresariado representa a hegemonia de um bloco de poder, e atua como "partido político" (GRAMSCI, 2000), no sentido de que este é o anunciador e organizador de uma concepção de mundo que tem influenciado nos princípios e objetivos da educação pública.

Segundo a Resolução no 2/2015, o movimento de "profissionalização docente" está relacionado com a organização de diretrizes nacionais responsáveis por definir princípios, fundamentos, dinâmica formativa, estrutura curricular e objetivo dos cursos de formação inicial e continuada dos (as) professores (as) da educação básica, segundo uma concepção ampla, plural, técnica e científica do que caracteriza o ato educativo nas instituições de ensino públicas. Como também, regulamentar os parâmetros nacionais de valorização do profissional do magistério, a ser considerado pelos sistemas e redes de educação Municipais, Estaduais, Federais e do Distrito Federal no processo de elaboração e gestão das políticas educacionais. Desta forma, entendemos que a relevância deste artigo consiste em analisar a valorização do magistério conforme a Resolução no 2/2015, que define as Diretrizes Curriculares Nacionais para formação inicial e continuada dos profissionais do magistério público, reconhecendo a materialidade das políticas em curso, que refletem nas condições de trabalho dos professores e que vem gerando uma metamorfose no mundo do trabalho docente nas redes municipais e estaduais de ensino.

O desenvolvimento teórico que nos auxilia parte de um recorte histórico e metodológico no qual o sentido social de uma política pública é apreendido para além de sua expressão fenomênica, posta por uma interpretação restrita da 'letra da lei'. Segundo este método de análise buscamos compreender, concretamente, o alcance das diretrizes da Resolução no 2/2015 para uma efetiva política de

\footnotetext{
${ }^{2}$ As 'Diretrizes Curriculares Nacionais para a Formação Inicial e Continuada dos Profissionais do Magistério da Educação Básica' foi elaborada mediante estudos sistematizados pela Comissão Bicameral do Conselho Nacional de Educação (CNE), inscrito no Parecer no 2/2015, instituída em Resolução n²/2015, e homologada pelo Ministério de Educação (MEC) em 2015.
} 
valorização do magistério público, em uma conjuntura de precarização do trabalho docente e capilarização do empresariado na educação pública, mediante uma política pública de cunho gerencialista e que objetiva racionalizar a gestão dos sistemas, redes e instituições de ensino a partir do controle do trabalho docente e das parcerias público-privadas. Mediante esta perspectiva analítica, acreditamos avançar no sentido da crítica, teórica e metodológica dos processos de incorporação do novo ethos empresarial na gestão da educação pública.

\section{AS POLÍTICAS DE PROFISSIONALIZAÇÃO MEDIANTE AS CONDIÇÕES DE TRABALHO DOCENTE}

A divisão social do trabalho, as formas de regulação, controle e autonomia no trabalho, estruturação das atividades escolares e a relação do número de alunos por professor, podem ser compreendidas como componentes das condições de trabalho docente. Ball $(2005 ; 2008)$ analisa tal processo desde uma perspectiva do caráter performático e regulador das políticas educativas que, ao alcançar os docentes, por meio de um endereçamento interpelativo das reformas gerencialistas, visam a um controle da subjetividade para forjar identidades docentes. Oliveira (2007) também desenvolve o tema da autointensificação do trabalho docente, demonstrando como os processos de intensificação, pela crescente precarização do trabalho e pelo aumento das funções e atividades docentes, advindos das novas formas de organização do trabalho impostas pelas reformas, vão se transformando em processos de autointensificação (DUARTE, 2010).

A temática é retomada por Garcia e Anadon (2009), que tratam de demonstrar relações entre as reformas educativas e a autointensificação do trabalho docente, indicando que a precarização do trabalho na educação básica, as novas demandas nos modos de gestão do trabalho escolar, envolvendo o currículo e o ensino, juntamente com as políticas oficiais de formação e profissionalização, estimulam uma nova moral, que impõe, por sua vez, uma nova identidade docente, baseada na responsabilização e na culpa. É um processo de subjetivação que, associado à intensificação, atinge as emoções docentes, resultando num processo de intensificação.

Este processo liga-se a outra questão fundamental para análise do trabalho docente, que é a jornada de trabalho ${ }^{3}$. Ao abordar o tema, Sady Dal Rosso nos oferece algumas pistas importantes. Segundo o sociólogo,

nos dias de hoje, a questão da duração da jornada transformou-se num problema social e de pesquisa de primeira ordem, por causa do impacto sobre a saúde dos trabalhadores. Há profissionais da

\footnotetext{
${ }^{3}$ Ao focar nossa análise na jornada de trabalho, não excluímos a existência de outros elementos importantes para a valorização dos profissionais do magistério. Não há consenso sobre o que significa a "profissionalização docente" e que ela, por si só, garantiria a valorização. Portanto, entrar neste debate não foi o objetivo deste artigo.
} 
educação que realizam jornadas entre 60 e 70 horas semanais. Com isso, avolumam-se os problemas de saúde física e emocional na categoria. Muitos docentes também se submetem a horas de trabalho não pago na preparação de aulas, correção de provas, no atendimento aos familiares dos alunos e em atividades coletivas nas escolas. A jornada é uma questão relevante por uma razão adicional, a saber, a luta pelo tempo livre. Dispor de tempo livre significa alargar o espaço de escolhas e de decisão para realizar atividades edificantes. Retomar a elaboração da teoria do valor trabalho, de modo que a classe trabalhadora tenha em mãos um princípio para a ação crítica é uma iniciativa desejável e necessária aos dias de hoje (DAL ROSSO, S. 2010. CDROM).

A jornada de trabalho se expressa primeiramente pelo componente de duração, que compreende a quantidade de tempo que o exercício profissional consome das vidas das pessoas, mas também se caracteriza pela intensificação, que tem a ver com o investimento das energias pessoais com o trabalho. Refere-se ao desgaste com o ofício. Neste caso, Assunção e Oliveira (2009), afirmam que a ampliação da jornada de trabalho pode ser analisada como um elemento que resulta na intensificação, seja por meio da extensão da jornada diária, seja pela redução das porosidades. $^{4}$ Trata-se de um aumento das horas e da carga de trabalho sem qualquer remuneração.

Deve-se considerar que, no caso dos docentes, o número de horas semanais efetivamente trabalhadas costuma ultrapassar o número de horas-aula informadas. Segundo Souza (2008), trata-se do diferencial entre tempo de ensino e tempo de trabalho, este último maior, englobando também o tempo empregado em preparação das aulas, correção de provas, estudos, realizados fora do horário escolar, que deveriam ser acrescidos ao tempo de ensino para melhor dimensionar a jornada de trabalho dos docentes.

A intensificação do trabalho que ocorre no interior da jornada remunerada é bastante preocupante por se tratar, em geral, de estratégias mais sutis e menos visíveis de exploração. Um fator indicativo de jornada ampliada de trabalho e intensificação do trabalho se refere ao número de unidades educacionais em que o sujeito docente trabalha. Nesses casos, o professor não se identifica com uma escola em particular, assume um número de aulas que não lhe permite conhecer e gravar o nome da maioria de seus alunos e acabam sem tempo para preparar aulas, estudar e se atualizar, dedicando boa parte de seus finais de semana a cuidar de questões do trabalho sobre as quais se encontra impedido durante a semana. Segundo informações da pesquisa coordenada por Codo (1999) com trabalhadores em educação básica, a carga mental elevada no trabalho, preponderante em

\footnotetext{
${ }^{4}$ A porosidade na jornada de trabalho é um conceito típico do fordismo, sendo considerada como buracos contidos na jornada de trabalho que se referem aos momentos em que o trabalhador vai ao sanitário, os tempos nos quais conversa com um colega pelos corredores, o tempo de descanso, etc.
} 
profissionais com mais de um vínculo empregatício e que trabalham em mais de um nível de ensino, o que provavelmente "implica em mais deslocamento, maior esforço de adaptação entre ambientes diferentes, preparação de atividades distintas" (CODO, 1999, p. 285) aparece associada a sintomas como exaustão emocional e despersonalização, ou seja, sentimentos de desânimo e desligamento afetivo, que se retroalimentam.

Consideramos que a valorização dos profissionais docentes compreende a articulação entre formação inicial, formação continuada, carreira, salários e condições de trabalho. Ações de diversas naturezas em relação à profissionalização docente necessitariam evidenciar melhorias nas perspectivas de carreira e alterar o imaginário coletivo relativo a esta profissão, tanto na sociedade em geral, como entre os próprios professores, o que passa, segundo Vaillant (2007, p. 8-9), "por devolver a esses profissionais a confiança em si mesmos, o que pode ser conseguido com políticas adequadas que perdurem no tempo". É preciso considerar aqui o que Fanfani (2005, p. 270-280) destaca: "docentes não são autômatos sociais cujas ações obedecem unicamente a estímulos externos, tais como as leis, decretos, circulares e regulamentos". As políticas públicas não podem ignorar este fato, pois mudanças de perspectivas e valores se constroem em vasos comunicantes e não meramente por um regulamento.

Nesse sentido, quanto aos princípios que norteiam a valorização do profissional do magistério da educação básica, destacamos no Capítulo VII da Resolução no 2/2015 a integração dessa política com o processo de formação inicial e continuada dos mesmos, e-caracterizada pela garantia de construção, definição coletiva, aprovação de planos de carreira e salário, com condições que assegurem jornada de trabalho com dedicação exclusiva ou em tempo integral a ser cumprida em um único estabelecimento de ensino e a destinação de 1/3 da carga horária de trabalho a outras atividades pedagógicas inerentes ao exercício do magistério (BRASIL, 2015, p. 15).

Assim como a Resolução no 2/2015, ressaltamos que a definição de uma jornada de trabalho compatível com a especificidade do trabalho docente está diretamente relacionada à política de profissionalização docente, à valorização do magistério, à qualidade do ensino e ao fortalecimento da construção da identidade profissional dos docentes da educação básica, uma vez que a utilização do tempo fora da sala de aula para realizar outras atividades ligadas ao planejamento do ensino interfere positivamente na qualidade das aulas e no desempenho do professor (SILVA, 2014).

Ressaltamos, entre outros pontos, a recuperação da dignidade do trabalho docente através da implantação da Lei do Piso Nacional Salarial Profissional (Lei 11.738/2008), na sua integralidade, prevendo-se a concentração do professor com dedicação integral e exclusiva a uma escola e o estabelecimento de $1 / 3$ das horas para as atividades de preparação e avaliação, pois, é de comum acordo que para um trabalho pedagógico se realizar de forma consistente, é preciso que haja dedicação 
do professor a um número pequeno de turmas e que ele atue preferencialmente em uma única instituição. Isto porque só desta maneira é possível criar uma relação de conhecimento, pertencimento e interação, fundamentais à prática pedagógica. $E$ hoje, a realidade é que um professor da educação básica dificilmente tem uma única matrícula e geralmente acumula vários empregos na esfera pública ou privada a fim de alcançar uma remuneração razoável. Nesse sentido, a fragmentação do tempo de trabalho de um professor tem sido alvo de muitos estudos e discussões ${ }^{5}$ e o cumprimento das leis que se referem à jornada de trabalho docente e ao tempo de planejamento pedagógico precisam ser efetivamente cumpridos pelos entes federados.

Deste modo, o que a resolução traz à tona, ressalta mais uma vez o que outras leis também apontam (como a Lei $n^{\circ}$ 11.738/2008) e diversos estudos e pesquisas sobre a valorização do profissional docente atentam há décadas. Ou seja, somente com uma dedicação exclusiva do professor a uma escola e com o tempo de planejamento cumprido efetivamente pelos governos dos estados e municípios, o trabalho docente pode se realizar de forma autônoma, plena e eficiente ${ }^{6}$.

\section{EMPRESARIAMENTO DA EDUCAÇÃo PÚBLICA E PRECARIZAÇÃO DE NOVO TIPO DE TRABALHO DOCENTE}

No âmbito da educação pública brasileira, desde a "reforma"" do Estado, as frações burguesas organizadas em entidades sociais sem fins lucrativos ganham força, tais como, o Grupo de Instituições e Fundações Empresarias (GIFE) ${ }^{8 i}$ e o

\footnotetext{
${ }^{5}$ Uma análise mais apurada sobre esse assunto pode ser encontrada em SILVA, A. M. Valores e Usos do Tempo dos Professores: a (con)formação de um grupo profissional. (Dissertação de mestrado) Faculdade de Educação, Universidade Federal do Rio de Janeiro, Rio de Janeiro: 2014. 172f. Nesta pesquisa buscamos entender a fragmentação do tempo dos professores da Rede Estadual do Rio de Janeiro. Verificamos que o fato de um professor ter sua matrícula dividida em várias escolas tem levado muitos profissionais a aderirem ao Programa Autonomia da Fundação Roberto Marinho/FIESP como forma de fuga à precarização das condições de trabalho.

${ }^{6}$ Importante destacar que a discussão posta com a Lei no 11. 738/2008 e a Resolução n02/2015, oculta a reivindicação histórica dos sindicatos mais combativos, que na década de 1990 definiam para a política de valorização docente o estabelecimento de 5 salários mínimos como parâmetro para o estabelecimento do Piso Nacional do Profissional do Magistério, no âmbito do Fórum Nacional em Defesa da Escola Pública (FNDEP).

7 Colocamos a palavra Reforma entre aspas por entender que na verdade tratou-se de uma "contrarreforma". Isso se dá pelo fato de considerar que a Reforma Administrativa do Aparelho do Estado (BRASIL, 1995), não acolheu, substancialmente, demandas da classe trabalhadora, ao contrário, instaurou um processo de retrocesso nas suas conquistas. Sobre o debate reforma e contrarreforma ver: COUTINHO, Carlos Nelson. A época neoliberal: revolução passiva ou contrareforma? Revista Novos Rumos. Campinas: Unicamp. V. 49. N. 1. Jan/jun, 2012 (p. 117 - 126).

Disponível em: http://www2.marilia.unesp.br/revistas/index.php/novosrumos/article/view /2383/1943 Acesso: 04 de março de 2012.

${ }^{8}$ Conforme inscrito no site do Gife, trata-se de uma "organização sem fins lucrativos que reúne associados de origem empresarial, familiar, independente ou comunitária, que investem em projetos de finalidade pública". Cuja missão é "aperfeiçoar e difundir conceitos e práticas do uso de recursos
} 
movimento Todos Pela Educação ${ }^{9}$ (TPE), legitimadas nas perspectivas da responsabilidade social e do investimento social privado ${ }^{10}$. Nestas, observa-se a dinâmica da obtenção da hegemonia por parte dos setores ligados ao capital financeiro, como Instituto Unibanco, Fundação Bradesco, Itaú Social; ao capital industrial, como o grupo Gerdau, Votorantim e Samarco; do agronegócio, além de outros setores da economia como Instituto Natura, Fundação Lemman, e grupos afins, como o Instituto Ayrton Senna, a Fundação Roberto Marinho, TV Globo, entre muitos outros, formando um amplo conglomerado empresarial visando 0 investimento social privado em educação e o protagonismo nas definições de políticas públicas de educação.

O papel desses reformadores empresariais da educação no Brasil é apresentado por Freitas (2012), onde levanta algumas das características que marcam a proposta destes "novos reformadores". As categorias centrais que definem esta política educacional envolvem uma combinação de responsabilização, meritocracia e privatização que reflete uma coalizão entre políticos, mídia, empresários, empresas educacionais, institutos, fundações privadas e pesquisadores alinhados com a ideia de que o modo de organizar a iniciativa privada é uma proposta mais adequada para "consertar" a educação, do que as propostas feitas pelos educadores profissionais: ideias muito inspiradas na educação americana, alvo de críticas de Diane Ravitch (2011) e bastante apropriadas para analisar a realidade brasileira.

$\mathrm{Na}$ medida em que a educação brasileira se expandiu, sobretudo nos segmentos do Ensino Fundamental e, mais recentemente, no próprio Ensino Médio, o interesse do empresariado em se inserir nas escolas aumentou. O movimento "Todos pela Educação", criado em 2006, propôs a "parceria" de todos os segmentos da sociedade, incluindo, sobretudo, seus fundadores e associados, com as escolas públicas, espaço de formação de milhões de jovens em todo o país (LEHER, 2011). A força de mobilização desse movimento está inserida em um contexto mais amplo de reorganização da sociabilidade da classe dominante no Brasil (NEVES, 2005), onde o

privados para o desenvolvimento do bem comum". Disponível em: http://gife.org.br/quem-somos/ Acesso em: 15 de setembro de 2016.

${ }^{9}$ Conforme inscrito no site, o "Todos Pela Educação", criado em 2006, "é um movimento da sociedade brasileira", "apartidário e plural", "que tem como missão contribuir para que até 2022, ano do bicentenário da Independência do Brasil, o país assegure a todas as crianças e jovens o direito a Educação Básica de qualidade." Seu objetivo "é ajudar a propiciar as condições de acesso, de alfabetização e de sucesso escolar, a ampliação de recursos investidos na Educação Básica e a melhora da gestão desses recursos". Disponível em: http://www.todospelaeducacao.org.br/quemsomos/o-tpe/ . Acesso em: 15 de agosto de 2016.

${ }^{10}$ As noções de responsabilidade social empresarial e de investimento social privado são definidas pelo Grupo de Institutos e Fundações Empresariais (GIFE, 2003) como ato de empreender ações inovadoras voltadas aos problemas sociais, por meio de rede social colaborativa e de forma a gerar resultados imediatos (Para ver mais sobre esse tema, ler MOTTA e SILVA, Professores da Rede Pública diante da precarização do trabalho: saídas coletivas de resistência ou adesão aos programas privatistas?, trabalho apresentado no VIII Congresso Latinoamericano de Estudos sobre o Trabalho: Buenos Aires, 2016. 
empresariado assumiu um projeto de hegemonia e passou a ter na escola pública um espaço de difusão.

Todo esse processo afeta a imagem do professor como um sujeito de exercício intelectual inalienável, pois a "assimilação" dos professores ao projeto das empresas busca retirar desses profissionais a sua autonomia na medida em que o projeto político pedagógico da escola passa a sofrer a mediação de instituições e projetos baseados no direito privado. Assim, não é a comunidade escolar que produz seus mecanismos internos de discussão do planejamento escolar e curricular, mas certos interesses empresariais passam a mediar escolhas, a partir de então determinadas por benefícios materiais (material didático, oferta de formação, etc.) e convencimentos ideológicos que são inerentes à entrada de projetos de educação privados na instituição pública de ensino. A escola "desinteressada" (GRAMSCI, 2011), aquela em que a formação dos jovens não se dá mediada por interesses privados, exige o caráter público que é antagônico ao processo de privatização exercido pelos programas privatistas-empresariais.

Compreendemos o fenômeno em questão, em um movimento de desqualificação de um determinado modo de realizar o trabalho docente, com vistas a sua requalificação em outra direção e sentido. No nosso ver, essa reconfiguração metamorfoseada do trabalho docente se insere no contexto de crise estrutural do trabalho e de reestruturação produtiva, que intensifica a precarização, perpassa os setores públicos de caráter estável-formal e adquire outras dimensões que não somente objetiva, mas também subjetiva.

Assim, consideramos que todo o processo gerado a partir das reformas educacionais nas últimas décadas leva a uma "precarização subjetiva" (LINHART, 2009) que tem íntima relação com a crescente presença de setores privatistas na educação brasileira pública com sua lógica de gestão e concepção de educação baseados na meritocracia e na remuneração por resultados, que perpassa pela necessidade de educar o professorado e quebrar a sustentação dos movimentos de resistência e contestatório da classe trabalhadora.

Com essa nova configuração das políticas, o que se observa é que o grau de autonomia do professor, mesmo que relativa, vem se tornando cada vez menor, seja pela ampliação de sua jornada de trabalho, seja pelo rebaixamento de seu nível de qualificação. A autonomia do trabalho docente vem sendo cada vez mais ameaçada, e isso é decorrente da expropriação dos instrumentos de produção do conhecimento, que buscam tornar os professores proletários, entregadores de conhecimento.

As formas gerais que o trabalho em educação assume, através dos processos, dos instrumentos de regulação e organização do trabalho escolar, do currículo como deterioração dos processos, impactam diretamente esse trabalhador e apontam para a sua "reconversão" (SHIROMA et. al, 2000), onde a hegemonia empresarial permite modelar um projeto de conformação dos trabalhadores no serviço público, e em especial na educação, para o trabalho flexível e também para sua atomização enquanto classe trabalhadora. Nesse sentido, a diminuição, ou até mesmo ausência 
do protagonismo do educador na produção do conhecimento é o principal aspecto que atualiza as teses de proletarização e desprofissionalização docente (Oliveira, 2004), pois os professores veem sua autonomia ser cada vez mais ameaçada, o que influencia diretamente na condição do processo de ensino aprendizagem.

Observa-se, dessa maneira, que a classe empresarial tem se organizado para garantir que todos esses elementos possam ser articulados ao seu favor, perpetuando a dominação, a começar pela intelectual. Nesse momento, a reorganização do trabalho docente implica na expropriação cultural e intelectual da formação clássica desses trabalhadores. O que exige maior controle do processo e adequação do trabalhador docente, implicando em mecanismos coercitivos visando ao melhor desempenho, eficiência e produtividade. Ou seja, o objetivo desses novos reformadores é buscar um processo de formação de uma camada de intelectuais que sejam assimilados pelo projeto hegemônico do bloco no poder.

\section{CONSIDERAÇÕES FINAIS}

Tomamos aqui uma postura reflexiva e crítica ao processo de incorporação do ethos empresarial, que objetiva o controle dos processos e dos resultados educacionais na gestão das instituições de ensino públicas de educação básica. Pois ainda não foi comprovado concretamente o efeito positivo dessa gestão empresarial, e, portanto, gerencialista para a universalização e democratização da educação pública, uma vez que essa política vem se mostrando deletéria para a formação cultural, humana, científica e tecnológica da classe trabalhadora (LEHER; EVANGELISTA, 2012; LEHER; MOTTA, 2014).

Buscamos compreender o fenômeno do trabalho docente em sua forma e seu conteúdo através das mediações que se apresentam através das relações de trabalho, das formas de inserção na carreira docente, de atuação no serviço público e de ingresso em programas privatistas dentro da lógica flexível. Partindo da hipótese de que os professores atuantes nas escolas públicas nas últimas décadas, envolvidos nas reformas educativas com base no ethos empresarial, têm suas condições de trabalho ainda mais precarizadas; diferentes aspectos confirmam a proposta aqui analisada, pois o atual movimento de entrada dos empresários na escola pública não tem contribuído para melhorar as condições de trabalho dos docentes, ao contrário, renovam as teses sobre a desprofissionalização e proletarização, agregando uma precarização de novo tipo que alcança de forma deletéria a subjetividade dos trabalhadores do magistério.

\section{REFERÊNCIAS BibLIOGRÁfICAS}

ASSUNÇÃO, Ada Ávila.; OLIVEIRA, Dalila Andrade. Intensificação do trabalho e saúde dos professores. In: Educação \& Sociedade. v. 30, n. 107, p. 349-372, 2009. 
BALL, Stephen. The education debate. Bristol: The Policy Press, 2008.

. Profissionalismo, gerencialismo e performatividade. In: Cadernos de Pesquisa. V.35, n.126, p. 539-564, set./dez. 2005.

BRASIL. Resolução $n^{\circ} 2$, de 1 de julho de 2015. Define as Diretrizes Curriculares Nacionais para a formação inicial em nível superior (cursos de licenciatura, cursos de formação pedagógica para graduados e cursos de segunda licenciatura) e para a formação continuada.

. Parecer $n^{\circ} 2$, de 9 de junho de 2015b. Diretrizes Curriculares Nacionais para a Formação Inicial e Continuada de Profissionais do Magistério da Educação Básica.

. Presidência da República (F.H.C.). Plano Diretor da Reforma do Aparelho do Estado. Brasília: Presidência da República, Câmara da Reforma do Estado. Ministério da Administração Federal e Reforma do Estado, 1995.

- Lei do Piso Salarial Profissional Nacional para os Profissionais do Magistério público da Educação Básica. (Lei no 11738/2008). Brasília, 2008.

CODO, Wanderley. Educação, carinho e trabalho. Petrópolis: Vozes, Brasília: CNTE/UNB, 1999.

COUTINHO, Carlos Nelson. A época neoliberal: revolução passiva ou contra-reforma? In: Revista Novos Rumos. Campinas: Unicamp. V. 49. N. 1. Jan/jun, 2012 (p. 117126). Disponível em: http://www2.marilia.unesp.br/revistas/index.php/novosrumos /article/view /2383/1943 Acesso: 4 de março de 2012.

DAL ROSSO, Sady. Verbete Jornada de trabalho. In: OLIVEIRA, D.A. DUARTE. A. M. C., VIEIRA, L. M. F. Dicionário: trabalho, profissão e condição docente. Belo Horizonte: UFMG/Faculdade de Educação, 2010. CDROM.

DUARTE, Adriana Maria Cancela. Intensificação do Trabalho Docente: In: OLIVEIRA D.A.; DUARTE, A. M. C.; VIEIRA. L. M. F. Dicionário: trabalho, profissão e condição docente. Belo Horizonte: UFMG/ Faculdade de Educação, 2010. CDROM.

FANFANI, Emilio Tenti. La condición docente: análisis comparado de la Argentina, Brasil, Perú y Uruguai. Buenos Aires: Siglo XXI Editores, 2005.

FREITAS. Luiz Carlos. Os reformadores empresariais da educação: da desmoralização do magistério à destruição do sistema público de educação. Educ. Soc., Campinas, v. 33, n. 119, p. 379-404, abr.-jun. 2012.

GARCIA, Maria Manuela Alves; ANADON, Simone Barreto. Reforma Educacional, intensificação e autointensificação do trabalho docente. Educação \& Sociedade, Campinas, v.30, n.106, p. 63-85, jan./abr, 2009. 
DOI: $10.12957 / e-m o s a i c o s .2017 .30254$

GRAMSCI, Antonio. O leitor de Gramsci: escritos escolhidos 1916-1935 / Carlos Nelson Coutinho, organizador. Rio de Janeiro: Civilização Brasileira, 2011.

- Cadernos do cárcere. v. 3: Maquiavel. Notas sobre o Estado e a política. Rio de Janeiro: Civilização Brasileira, 2000.

LEHER, Roberto. Desafios para uma educação além do capital. In. István Mészáros e os desafios do tempo histórico. São Paulo: Ed. Boitempo, 2011.

; EVANGELISTA, Olinda. Todos pela educação e o episódio Costin no MEC. In: Trabalho Necessário. Disponível em: www.uff.br/trabalhonecessario. Ano 10, no $15 / 2012$.

; MOTTA, Vânia. Capitalismo dependente reserva um futuro hostil para a juventude: educação, precariado, exército industrial de reserva e irrupção das jornadas de junho no Brasil. No prelo, 2014.

LINHART, Daniéle. Modernisation et précarisation de la vie au travail. Papeles del CEIC, n. 43, 2009. Disponível em: http://www.identidadcolectiva.es/pdf/43.pdf Acesso em 22 de março de 2016.

MOTTA, Vânia; SILVA, Amanda Moreira. Professores da rede pública diante da precarização do trabalho: saídas coletivas de resistência ou adesão aos programas privatistas? In: VIII Congresso Latinoamericano de Estudos sobre o Trabalho: Universidade de Buenos Aires, ago, 2016.

NEVES, Lucia Maria Wanderley. A nova pedagogia da hegemonia: estratégia do capital para educar o consenso. São Paulo, Ed. Xamã, 2005.

OLIVEIRA, Dalila Andrade. Política educacional e re-estruturação do trabalho docente: reflexões sobre o contexto Latino-americano. In: Educação e Sociedade, vol.28, n.99, p. 355-375, 2007.

A reestruturação do trabalho docente: precarização e flexibilização. In: Revista Educ. Soc., Campinas, vol. 25, n. 89, p. 1127-1144, Set./Dez. 2004.

RAVITCH, Diane. Vida e Morte do grande sistema escolar americano: como os testes padronizados e o modelo de mercado ameaçam a educação. Porto Alegre: Sulina, 2011.

SHIROMA, Eneida Oto; MORAES, Maria Célia Marcondes de, EVANGELISTA Olinda. Política educacional. Rio de Janeiro: DP\&A, 2000.

SILVA, Amanda Moreira. Valores e Usos do Tempo dos Professores: a (con)formação de um grupo profissional. 2014. 172f. Dissertação (Mestrado) - Faculdade de Educação, Universidade Federal do Rio de Janeiro, Rio de Janeiro, 2014. 
e-Mosaicos - Revista Multidisciplinar de Ensino, Pesquisa, Extensão e Cultura

DOI: $10.12957 /$ e-mosaicos.2017.30254

SOUZA, Aparecida Neri de. Condições de trabalho na carreira docente: comparação Brasil-França. In: COSTA, A. de O.; SORJ, B.; HIRATA, H.; BRUSCHINI, C. (Orgs.) Mercado de trabalho e gênero: comparações internacionais. Rio de Janeiro:

Fundação Getúlio Vargas, 2008. P. 355-372.

VAILLANT, Denise. Los docentes em primer plano. Lima: PREAL, 2007. 